BMJ Open

Sport \&

Exercise

Medicine

\title{
Variation in lifting kinematics related to individual intrinsic lumbar curvature: an investigation in healthy adults
}

\author{
Anastasia V Pavlova, ${ }^{1}$ Judith R Meakin, ${ }^{2}$ Kay Cooper, ${ }^{3}$ Rebecca J Barr, ${ }^{1,4}$ \\ Richard M Aspden ${ }^{1}$
}

To cite: Pavlova AV, Meakin JR, Cooper $\mathrm{K}$, et al. Variation in lifting kinematics related to individual intrinsic lumbar curvature: an investigation in healthy adults. BMJ Open Sport \& Exercise Medicine 2018;4:e000374. doi:10.1136/ bmjsem-2018-000374

- Additional material is published online only. To view please visit the journal online (http://dx.doi.org/10.1136/ bmjsem-2018-000374).

Accepted 25 June 2018

\section{Check for updates}

(c) Author(s) (or their employer(s)) 2018. Re-use permitted under CC BY-NC. No commercial re-use. See rights and permissions. Published by BMJ.

${ }^{1}$ Arthritis and Musculoskeletal Medicine, School of Medicine, Medical Sciences and Nutrition, University of Aberdeen, Aberdeen, UK

${ }^{2}$ Biophysics Research Group, College of Engineering Mathematics and Physical Sciences, University of Exeter, Exeter, UK

${ }^{3}$ School of Health Sciences, Robert Gordon University, Faculty of Health and Social Care, Aberdeen, UK ${ }^{4}$ Medicines Monitoring Unit (MEM0), Division of Molecular \& Clinical Medicine, School of Medicine, University of Dundee, Dundee, UK

Correspondence to Dr Richard M Aspden; $r$ aspden@abdn.ac.uk

\section{ABSTRACT}

Objective Lifting postures are frequently implicated in back pain. We previously related responses to a static load with intrinsic spine shape, and here we investigate the role of lumbar spine shape in lifting kinematics.

Methods Thirty healthy adults (18-65 years) performed freestyle, stoop and squat lifts with a weighted box (6-15 $\mathrm{kg}$, self-selected) while being recorded by Vicon motion capture. Internal spine shape was characterised using statistical shape modelling (SSM) from standing midsagittal MRIs. Associations were investigated between spine shapes quantified by SSM and peak flexion angles. Results Two SSM modes described variations in overall lumbar curvature (mode 1 (M1), 55\% variance) and the evenness of curvature distribution (mode 2 (M2), 12\% variance). M1 was associated with greater peak pelvis $(r=0.38, p=0.04)$ and smaller knee flexion $(r=-0.40$, $\mathrm{p}=0.03$ ) angles; individuals with greater curviness preferred to lift with a stooped lifting posture. This was confirmed by analysis of those individuals with very curvy or very straight spines ( $|\mathrm{M} 1|>1 \mathrm{SD}$ ). There were no associations between peak flexion angles and mode scores in stoop or squat trials ( $p>0.05$ ). Peak flexion angles were positively correlated between freestyle and squat trials but not between freestyle and stoop or squat and stoop, indicating that individuals adjusted knee flexion while maintaining their preferred range of lumbar flexion and that 'squatters' adapted better to different techniques than 'stoopers'.

Conclusion Spinal curvature affects preferred lifting styles, and individuals with curvier spines adapt more easily to different lifting techniques. Lifting tasks may need to be tailored to an individual's lumbar spine shape.

\section{INTRODUCTION}

Manual lifting has been implicated as a contributor to low back pain (LBP), ${ }^{12}$ which remains first of the leading causes of global disability worldwide. ${ }^{3}$ LBP is particularly prevalent in manually demanding occupations requiring lifting. Although biopsychosocial factors play a large part in the development of chronicity, ${ }^{45}$ it has been suggested that the onset of LBP has a mechanical origin ${ }^{6}$ and that there is a link between the posture adopted during lifting and injury, through
Summary

- The natural shape of the lumbar spine in standing how lordotic it is, was associated with an individual's preference to squat or to stoop to lift a weight from the floor.

- Individuals with curvier spines preferred to stoop, and those with straighter spines preferred to squat in freestyle lifts.

- Natural 'squatters' adapted more easily to stooping than natural 'stoopers' to squatting.

- Lifting styles tailored to each individual may be important to avoid potentially damaging manoeuvres.

suboptimal load transfer $^{78}$ and subsequent tissue overload. ${ }^{8-10}$ Commonly investigated lifting techniques include squatting and stooping, as well as naturally chosen lifting styles (freestyle), but no consensus yet exists on which methods of lifting are the safest.

Current UK Health and Safety Executive (HSE) lifting guidelines state that 'at the start of the lift, slight bending of the back, hips and knees is preferable to fully flexing the back (stooping) or fully flexing the hips and knees (squatting)...don't flex the back any further while lifting'. ${ }^{11}$ The USA, however, still advocates the knees bent-straight back approach. ${ }^{12}$ The importance of a lumbar lordosis for a human's ability to support loads was first highlighted by Farfan, ${ }^{13}$ and has since been conceptualised by Aspden ${ }^{7}$ in the arch model, demonstrated ex vivo in isolated spine units by Crisco et $a l^{15}$ and further developed in the follower load principle by Patwardhan and colleagues. ${ }^{16}$ This approach suggests that, rather than generating moments, the musculature closely surrounding the spine is required to constrain the load to follow the curvature of the spine, providing compressive force to maintain stability, and to control the curvature to produce flexion and extension. More recent modelling studies have shown that curvature is one of the biggest factors associated with changes in spinal loading. ${ }^{17-19}$ 
Lumbar curvature is determined by several factors, including disc wedging, pelvic incidence, ${ }^{20}$ sacral slope, body weight distribution, vertebral body wedging and passive tissue strain, ${ }^{21}$ and is associated with familial and genetic factors. ${ }^{22} 23$ There is substantial variability in spinal curvature between individuals, ${ }^{24-27}$ and recently we have demonstrated, using statistical shape modelling (SSM), that each individual has a signature (intrinsic) lumbar spine shape. ${ }^{2829}$ One of the benefits of SSM is that it captures information on the entire shape of the spine, unlike angular measures ${ }^{25} 30$ which do not easily describe the distribution of curvature between the measured endplates. The accuracy, precision and reliability of SSM in describing spinal shape have been proven. ${ }^{28} 3132$

The aim of this study, therefore, was to test the hypothesis that differences in movement would be present between individuals with different lumbar curvatures. Using a cohort of healthy adults, our objectives were (1) to characterise lumbar spine shape using SSM and investigate the associations between spine shape modes and kinematics when lifting freestyle; and (2) to investigate whether their preferences remained even when instructed to squat or stoop.

\section{METHODS}

Thirty healthy adults between 18 and 65 years of age were recruited from the Aberdeen area, particularly university staff and students. Volunteers were included if they were currently free from back pain and had been during the previous 12 months, had not had any spinal surgery nor had any diagnosed spinal disorders. Data collection occurred over two sessions less than 2 weeks apart. The first session involved MRI of the spine, and the second took place in a human performance laboratory where a biomechanical analysis of lifting technique was performed. Height and weight were measured in the first session and body mass index (BMI) calculated as weight/ (height) ${ }^{2}$.

\section{Imaging}

MRIs of the lumbar spine were acquired using a Fonar 0.6T Upright pMRI scanner (Fonar Corporation, Melville, New York) while participants stood in a natural upright posture. Sagittal T2-weighted images were acquired using a multislice fast spin echo sequence (repetition time (TR)/relaxation time (TE) 2023.1/140 ms, $10 \mathrm{~mm}$ slice thickness with a $1 \mathrm{~mm}$ gap) on a $256 \times 160$ matrix with a $40 \mathrm{~cm}$ field of view. For each participant, the mid-sagittal slice was identified and converted to a $256 \times 256$ matrix in Image J (Wayne Rasband, National Institutes of Health, USA) and saved in bmp format for analysis. Lumbar spine angle was measured as the angle between lines tangential to the superior first lumbar (L1) and sacral (S1) vertebral endplates, to facilitate comparison with other cohorts.

\section{Motion capture}

A 13-camera Vicon MX motion capture system (Vicon Motion Systems, Oxford Metrics, UK) sampling at 100
$\mathrm{Hz}$ was used for motion analysis. After measuring height and weight, retroreflective markers were affixed to each participant's skin according to previously developed marker-sets and models for the lower limbs and pelvis ${ }^{33}$ and the lower back ${ }^{34} 35$ (details can be found in online supplementary information).

\section{Task}

The task was to lift a weighted box fitted with handles $\left(35.5 \mathrm{~cm}^{2} \times 24 \mathrm{~cm}\right.$ high) from the floor with two hands. To match the task to the individual, the weight was gradually increased by adding $1 \mathrm{~kg}$ discs into the $5 \mathrm{~kg}$ box until the participant reported being at $70 \%$ of their maximum effort. The mean (SD) weight lifted was $10.0(2.2) \mathrm{kg}$. Measured tasks used three different lifting techniques. First is without any instruction (freestyle), in an attempt to encourage their naturally preferred lifting motion. Then participants were instructed to squat ('keep the back straight and bend at the knees') and stoop lift ('keep the legs straight and bend at the back') in random order (online supplementary figure S2). Recording began from standing upright with the box at the toes and ended when the box had been lifted in front of the body and held close to the body at arm's-length. Three repetitions of each lifting technique were performed with up to a minute rest in between.

\section{Data analysis}

\section{Shape modelling}

SSM was used to describe variations in mid-sagittal lumbar spine (L1-S1) shape from MRIs as described previously. ${ }^{29} 31$ SSM involved a semiautomated placement of a 168-point template around the vertebral edges (online supplementary figure S3, online supplementary information), created using Active Appearance Modelling tools from the University of Manchester, UK (https://personalpages.manchester.ac.uk/staff/timothy. f.cootes/software/am_tools_doc/index.html). First, the spine templates in each image were aligned by scaling, rotation and translation (Procrustes transformation). Second, principal components analysis was performed on the coordinates to identify linearly independent patterns (modes of variation) describing shape variation in the whole cohort. Each mode had a mean of 0 and unit SD, and each image was assigned a score for each mode ${ }^{3637}$ describing how many SD it lay from the mean. Interpretation of the modes was aided by calculating intersegmental and lordosis angles for each mode varied by \pm 2 SD using MATLAB V.2012a (MathWorks, Natick, Massachusetts) (figure 1).

\section{Kinematic analysis}

Kinematic modelling was done using Vicon Nexus V.1.7 (Vicon Motion Systems, Oxford Metrics). Trajectories were filtered using a fourth-order low-pass Butterworth filter with a cut-off frequency of $12 \mathrm{~Hz}$, determined following a residual analysis ${ }^{38}$ and visual inspection of the data. A combination of lower body and low back models 


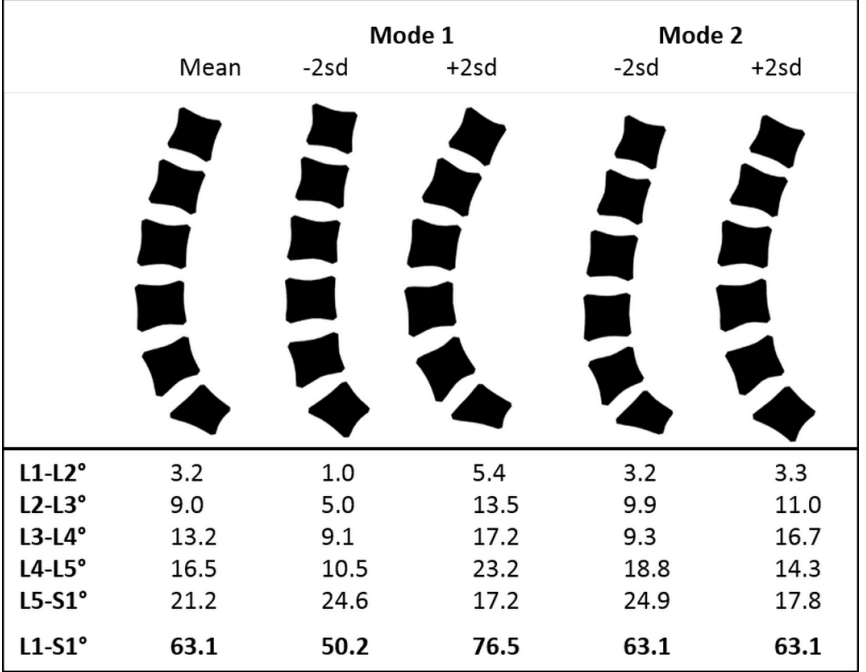

Figure 1 Average lumbar spine shape (mean) in standing identified by shape modelling $(n=30)$ and the first two modes of variation (mode 1 and mode 2). The total (L1-S1) and intersegmental angles demonstrate the amount and distribution of curvature within each mode when separately varied by $\pm 2 S D$.

developed at the University of Western Australia ${ }^{33-35}$ was adapted and used for kinematic modelling of the data. Lower limb anatomical and segment coordinate systems were defined according to the International Society of Biomechanics standards ${ }^{39}$ (see online supplementary information for more details).

\section{Statistical analysis}

Statistical analysis was performed using SPSS V.21. Normality was tested with the Shapiro-Wilk test. Correlations were performed to explore associations between peak kinematic variables and mode scores. Subsequently, individuals were grouped by mode 1 scores $(<-1$ SD and $>+1 \mathrm{SD}$ ), and differences between the groups' peak kinematics were analysed by independent samples t-tests or a Mann-Whitney test depending on normality. Finally, Pearson's correlation (and Spearman's where appropriate) was used to examine the associations between peak kinematic variables in all three trials (freestyle, squat and stoop) for all participants, and analysis of covariance
(ANCOVA) was used to test the associations between trial type (freestyle, squat and stoop) and peak kinematics while controlling for covariates (knee and lumbar flexion angles).

\section{RESULTS}

Thirty healthy adults (15 male, 15 female) were included in the study. Men were taller, heavier and had greater BMI than women $(\mathrm{p}<0.05)$, but their lumbar lordosis angle was not significantly different (table 1 ).

\section{Shape modelling of the lumbar spine}

Shape modes are ranked in descending order of variance. The first mode (M1) accounted for $55 \%$ of the variance and described variations in the overall curvature ('curviness'), ranging from a large lordosis to an almost straight spine. Mode 2 (M2) explained $12 \%$ of variance and described whether the curvature was distributed evenly or concentrated in the lower lumbar spine ("evenness') (figure 1). Subsequent modes were smaller and described more subtle variations in vertebral and spinal shape and were not analysed further. There were no differences in curviness or evenness between men and women (table 1).

\section{Freestyle lifting kinematics and spinal shape}

Peak flexion angles at any joint were not related to subject height and weight or the weight of the box lifted $(p>0.05)$. The associations between peak flexion angles at various joints are shown in table 2 . Individuals who flexed more at the knees had less lumbar and pelvic flexion but also flexed more at the hips. Peak pelvis and knee flexion angles were significantly correlated with curviness (M1) but not evenness (M2) (table 2).

Freestyle lifting kinematics were then compared between individuals at opposite ends of the distribution of curvatures (more than $1 \mathrm{SD}$ from the mean), thus creating curvy extreme (curvy ${ }_{\text {ext }}, M 1>+1, n=3$ ) and straight extreme (straight ${ }_{\text {ext }}, \mathrm{M} 1<-1, \mathrm{n}=5$ ) groups. The patterns of motion in the lumbar spine, pelvis and knee were clearly different between these groups (figure 2). In these groups combined $(n=8)$, M1 was strongly associated with peak lumbar and pelvis flexion

Table 1 Participant characteristics presented as mean (SD), except for age where the ranges are given

\begin{tabular}{lccc} 
& $\begin{array}{l}\text { Male } \\
(\mathbf{n = 1 5})\end{array}$ & $\begin{array}{l}\text { Female } \\
(\mathbf{n = 1 5})\end{array}$ & $\begin{array}{l}\text { All } \\
(\mathbf{N}=\mathbf{3 0})\end{array}$ \\
\hline Age (range) (years) & $31.3(21-52)$ & $27.7(20-50)$ & $29.5(20-52)$ \\
\hline Height (cm) & $176.2(5.3)^{\star}$ & $166.8(4.1)^{\star}$ & $171.5(6.7)$ \\
Weight (kg) & $78.7(11.5)^{\star}$ & $63.6(7.9)^{*}$ & $71.2(12.4)$ \\
Body mass index $\left(\mathrm{kg} / \mathrm{m}^{2}\right)$ & $25.3(3.2)^{\star}$ & $22.8(2.5)^{\star}$ & $24.1(3.1)$ \\
Lumbar lordosis $\left(^{\circ}\right)$ & $63.2(6.6)$ & $63.7(8.2)$ & $63.4(7.3)$ \\
Mode 1 & $-0.069(0.338)$ & $0.067(0.462)$ & - \\
Mode 2 & $0.039(0.175)$ & $-0.041(0.201)-$ & - \\
\hline
\end{tabular}

*Significant difference between male and female at $p<0.05$. 
Table 2 Correlation coefficients, $r$ (p values), between peak flexion angles at the various joints and spine shape mode scores for all 30 individuals performing a freestyle lift. .

\begin{tabular}{|c|c|c|c|c|c|c|}
\hline & \multicolumn{6}{|c|}{ Peak flexion angles } \\
\hline & Lumbar & Pelvis & Upper lumbar & Lower lumbar & Knee & Hip \\
\hline Pelvis & $0.92^{\star \star *}$ & - & & & & \\
\hline Upper lumbar & $0.64^{\star * *}$ & $0.37^{*}$ & - & & & \\
\hline Lower lumbar & $0.63^{\star \star *}$ & 0.33 & $0.73^{\star \star *}$ & - & & \\
\hline Knee & $-0.86^{* * *}$ & $-0.81^{* * *}$ & $-0.60^{* * *}$ & -0.50 * & - & \\
\hline Hip & $-0.66^{\star * *}$ & $-0.57^{\star *}$ & $-0.64^{\star * \star}$ & $-0.55^{\star *}$ & $0.64^{\star \star *}$ & - \\
\hline \multicolumn{7}{|l|}{ Shape modes } \\
\hline Mode 1 & $0.31(0.09)$ & $0.38(0.04)^{*}$ & $-0.05(0.81)$ & $0.06(0.75)$ & $-0.4(0.03)^{*}$ & $-0.11(0.57)$ \\
\hline Mode 2 & $0.32(0.09)$ & $0.33(0.07)$ & $0.21(0.26)$ & $0.13(0.48)$ & $-0.1(0.59)$ & $-0.02(0.91)$ \\
\hline
\end{tabular}

Significantly correlated at ${ }^{*} \mathrm{p}<0.05,{ }^{* \star} \mathrm{p}<0.01,{ }^{* \star *} \mathrm{p}<0.001$. Mode $1=$ curviness; mode $2=$ evenness.

The lumbar region was subdivided as described in online supplementary information.

and negatively correlated with knee flexion (table 3 ). In figure 2 , the peak flexion of those with curvier spines was, on average, $15^{\circ}$ more at the back and $12^{\circ}$ more at the pelvis than those in the straight group. Straight ${ }_{\text {ext }}$ individuals had, on average, $37^{\circ}$ greater peak flexion at the knees than curvy ${ }_{\text {ext }}$ (Mann-Whitney, $\mathrm{p}=0.04$ ) during freestyle lifting.

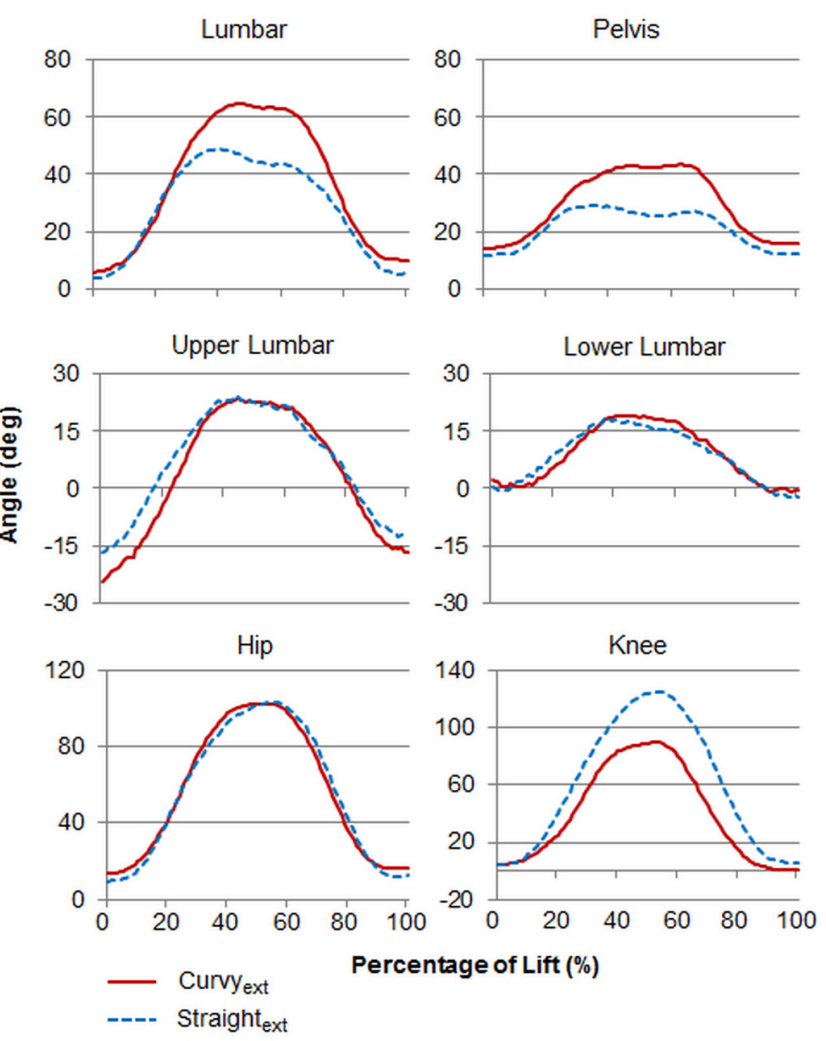

Figure 2 Mean flexion angles during symmetrical lifting, beginning from unloaded upright standing and finishing standing with a weighted box in the hands. Grouped by mode 1 (curviness) score into curvy ${ }_{\text {ext }}(>1$ SD from mean) and straight $_{\text {ext }}(<-1$ SD from mean) spine shape groups.
Comparison of lifting techniques in the context of spine shape We found no associations between peak flexion angles and mode scores, or any differences between curvy ${ }_{\text {ext }}$ and straight $_{\text {ext }}$ groups, in either stoop or squat trials ( $p>0.05$ ). However, the differences found in freestyle lifting led us to consider whether their preferences would affect the instructed squat and stoop trials. The associations between peak flexion angles in all three lifting styles were tested within the entire study sample $(\mathrm{N}=30)$. All peak flexion angles were positively correlated between freestyle and squat trials, but no correlations were found between freestyle and stoop or between squat and stoop (table 4). After controlling for peak knee flexion, ANCOVA revealed that peak lumbar flexion was no longer associated with the type of trial (freestyle, squat or stoop), indicating that, when asked to adopt a specific lifting technique, individuals predominantly altered the lifting style by increasing or decreasing flexion at the knees while maintaining their preferred range of lumbar flexion.

\section{DISCUSSION}

In this study we have shown that the curviness of the lumbar spine is associated with the way in which individuals lift a weight from the floor. When no instruction was given, individuals with more lordotic lumbar spines preferred to stoop down to pick up the box, while those with straighter spines preferred to squat. Our results also suggest that these natural movement preferences are maintained when instructions are given, especially in individuals with curvier spines who prefer to lift by stooping. In changing between lifting styles, individuals adjusted their knee flexion while maintaining their preferred lumbar flexion range.

\section{Spinal intrinsic curvature affects lifting styles}

Where analysis of the whole cohort provides an overall view of the kinematics, isolating the extremes enabled us to visualise better the contrast between the behaviours of curvy and straight spines. While this reduced the overall 
Table 3 Correlations, $r$ ( $p$ values), between peak flexion angles and spine shape mode scores for extreme spine shape groups $(n=8)$

\begin{tabular}{lllllll}
\hline & Lumbar & Pelvis & Upper lumbar & Lower lumbar & Knee & Hip \\
\hline Mode 1 & $\mathbf{0 . 7 9 ( 0 . 0 2 )}$ & $\mathbf{0 . 7 9 ( 0 . 0 2 )}$ & $0.12(0.78)$ & $0.24(0.57)$ & $-0.88(0.004)$ & $-0.33(0.42)$ \\
Mode 2 & $0.25(0.55)$ & $0.25(0.55)$ & $0.58(0.13)$ & $0.02(0.96)$ & $-0.20(0.63)$ & $-0.19(0.64)$ \\
\hline
\end{tabular}

Values in bold are significantly correlated at $p<0.05$. Mode $1=$ curviness; mode $2=$ evenness.

statistical power, it made significant the correlation between curviness and lumbar motion in the extreme groups. Although the relationship between M2 and peak lumbar and pelvic flexion was not far from significance when all 30 individuals were analysed, this was attenuated when only the extreme subsets were analysed. It is difficult to comment on whether this attenuation is due to the extremes of curvature obscuring the role of M2 or if this is due to a smaller group size. A larger sample size would allow us to explore this relationship in future studies. Those in the middle of the M1 distribution appeared to have more choice in how they lifted and their behaviour was less distinct. Because individuals with curvy and straight spines had different preferences when lifting freely, this posed the question of how this might affect their technique when instructed to lift in a particular way. Comparisons between the peak kinematics in freestyle lifting with those in squat and stoop trials showed that all flexion angles were positively correlated between freestyle and squatting. This indicates that, for example, individuals who lifted with more flexion at the back during freestyle also flexed more at the back when squatting. This similarity in movement, however, was not apparent between freestyle and stoop or between squat and stoop trials, hence suggesting an inability of the natural stoopers to adopt the prescribed styles as competently as the natural squatters. After controlling for knee flexion, lumbar flexion angles were no longer related to the type of lift, suggesting individuals altered their lifting style primarily by altering flexion at their lower limbs, while retaining similar motion at the back to their freestyle motion.

\begin{tabular}{|c|c|c|}
\hline & Squat & Stoop \\
\hline \multicolumn{3}{|l|}{ Freestyle } \\
\hline Lumbar & $0.67(<0.001)$ & $0.31(0.09)$ \\
\hline Pelvis & $0.39(0.03)$ & $0.22(0.24)$ \\
\hline Upper lumbar & $0.75(<0.001)$ & $-0.03(0.88)$ \\
\hline Lower lumbar & $0.83(<0.001)$ & $0.10(0.59)$ \\
\hline Нip & $0.69(<0.001)$ & $0.06(0.76)$ \\
\hline Knee & $0.57(0.001)$ & $0.11(0.57)$ \\
\hline
\end{tabular}

Values shown in bold are significantly correlated.

\section{Imaging approaches to record lifting manoeuvres}

To our knowledge, no studies have yet related preferred spinal movement for load lifting to an individual's baseline, intrinsic, spinal curvature, although a previous study found a relationship between lordosis angle and peak intervertebral flexion at individual segmental levels. ${ }^{40}$ The use of positional MRI has enabled us to image individuals in their normal standing posture, although not during the lifting manoeuvre itself. Relating overall kinematics to the movement of vertebrae invariably requires some form of imaging, some of which incurs a radiation dose. Some of the first direct measures of vertebral movement were performed by Breen and colleagues ${ }^{41} 42$ using videofluoroscopy to assess patients with mechanical dysfunction of the spine. Later Cholewicki and McGill $^{43}$ also used videofluoroscopy to record vertebral motion during heavy lifting (deadlifts) in four powerlifters but found only minor differences in motion between the lifters. They did not discuss whether motion was related to the lifter's standing vertebral angles. More recently Aiyangar and colleagues ${ }^{44}$ used dynamic stereoX-ray imaging, combined with subject-specific bone models constructed from CT images, to track intersegmental kinematics during the extension phase of lifting in 11 healthy volunteers. Although they provide valuable insights into segmental contribution to internal spine movement during lifting, they do not assess how this relates to the participant's baseline curvature. Harvey and colleagues ${ }^{45}$ performed videofluoroscopic imaging on a small sample of symptomatic volunteers and found similarities in motion patterns of the lumbar vertebral column relative to $\mathrm{S} 1$ between individuals with some lumbar disc conditions but not others.

\section{Possible mechanisms}

Flattening of the lumbar lordosis is suggested to cause considerable increases in spinal loads, ${ }^{146}$ and the stoop technique is generally believed to result in greater peak lumbar loads. ${ }^{47} 48$ Consequently, it might be thought that curvier individuals, who tend to stoop, are at a greater risk of overload and injury. However, lumbar vertebrae are able to withstand very high loads, ${ }^{15}{ }^{49-51}$ especially in pure compression, with the NIOSH lifting weight limits being based on vertebral compressive strength. ${ }^{52} 53$ The intervertebral disc is at greater risk when compressive forces are combined with bending or twisting. ${ }^{54-59}$ Kingma and colleagues ${ }^{60}$ suggest using one hand on the thigh as a support during single-handed squat lifting to 
reduce forces and overall moments on the spine. In addition, the arch model ${ }^{14}$ and the follower load principle $\mathrm{e}^{1617}$ indicate that bending moments and shear forces in the spine can be minimised by ensuring the thrust line is constrained to run along the centroid of the vertebral bodies so it generates pure compression. The shape of the spine during the lift then becomes important, and it has been suggested that maintaining some lordosis during lifting is advantageous for spinal stability. ${ }^{7} 1643$ On this basis, we could speculate that individuals with straighter spines unconsciously squatted to avoid lumbar flexion and maintain whatever lordosis they had.

People with straighter (hypolordotic) spines had a preference for a lifting style that is closer to that described by the HSE lifting guidelines, while those with curvier (hyperlordotic) spines had a different preference. Our results are comparable with those of du Rose and Breen, ${ }^{40}$ who found that a greater degree of lordosis was related to greater peak intervertebral flexion at individual segmental levels. Together these findings suggest that those with straighter spines chose to squat as a means to reduce loading on the spine. It also highlights the need to examine further, ideally using weightbearing imaging, the preference for a stooped posture and tendency towards greater intervertebral flexion in lordotic individuals and whether this is a more efficient and safer movement strategy, especially during manual lifting. In relation to the participants in this study, it would appear that the HSE guidelines are best suited to those in the middle of the shape spectrum and do not fit well with those that lie towards the extremes.

The main limitations of this study are the sample size and generalisability. Although a wide range of ages are represented, this relatively small group from a specific background may mean that the full range of variability in the general population has not been captured sufficiently. However the mean lumbar lordosis of this cohort is comparable with other postural studies, with an angle of $63.4^{\circ}\left(7.3^{\circ}\right)$ in erect standing (L1-S1) compared with previously published cohorts reporting mean angles of $61^{\circ}\left(\mathrm{SEM}, 12^{\circ}\right)^{61}$ and $61^{\circ}\left(10^{\circ}\right) .^{25}$ The weight lifted was standardised by an individual's perception of what they considered 'heavy' rather than by a more objective measure. While others have calculated a lifting weight using an individual's maximal voluntary contraction, the logistics of this study made that difficult and we found no relationship between weight lifted and peak flexion angles. A previous study using controlled weights also found no significant effect of load on the thoracic and lumbar spine kinematics. ${ }^{62}$ Here we only present data on peak angles and it would be instructive to examine the entire movement.

\section{CONCLUSIONS}

In this study we have demonstrated contrasting movement preferences during lifting between individuals with curvier and straighter lumbar spine curvatures. The data presented here highlight the importance of individual variability in lumbar spine curvature when analysing and comparing lifting manoeuvres. These results could be important for a reassessment of lifting guidelines, one size does not fit all, and for training of athletes where a given task may place different demands on different athletes depending on their natural lifting technique, which may depend on the shape of their lumbar spine.

Acknowledgements We thank B MacLennan and Baljit Jagpal for acquisition and consultation on MRl; Jacqueline Alderson (The University of Western Australia) and her team for training on and use of their model; and Dr Mandy Plumb for performing the preceding pilot studies.

Contributors AVP performed the data collection, data analysis and contributed to the interpretation of the data. She drafted the first version of the manuscript, critically revised the manuscript and approved the final article. JRM, KC and RJB contributed to the design of the study and the interpretation of the data, critically revised the manuscript and approved the final article. RMA contributed to the design of the study, the interpretation of the data, performed the critical revisions from the comments returned by coauthors and approved the final article.

Funding AVP was supported by a PhD studentship kindly donated by Roemex to the Aberdeen Centre of the Oliver Bird Rheumatism Programme at the Nuffield Foundation.

Disclaimer The funders played no part in the study design, in the collection, analysis and interpretation of data; in writing the manuscript; or in the decision to submit the manuscript for publication.

Competing interests None declared.

Patient consent Not required.

Ethics approval The study was approved by the College Ethics Review Board at the College of Life Sciences and Medicine, University of Aberdeen, and the School Research Review Group at the School of Health Sciences, Robert Gordon University, Aberdeen. Participants gave prior written consent.

Provenance and peer review Not commissioned; externally peer reviewed.

Data sharing statement Data are available on request through DaSH (https:// www.abdn.ac.uk/iahs/facilities/grampian-data-safe-haven.php) once appropriate new study permissions are in place. Initial contact via AMND Steering committee ( amnd@abdn.ac.uk). This process is in place to ensure that the use of data from this study is within the bounds of consent given previously by study participants.

Open access This is an open access article distributed in accordance with the Creative Commons Attribution Non Commercial (CC BY-NC 4.0) license, which permits others to distribute, remix, adapt, build upon this work non-commercially, and license their derivative works on different terms, provided the original work is properly cited, appropriate credit is given, any changes made indicated, and the use is non-commercial. See: http://creativecommons.org/licenses/by-nc/4.0/

\section{REFERENCES}

1. Bewick N, Gardner D. Manual handling injuries in health care workers. Int J Occup Saf Ergon 2000;6:209-21.

2. HSE. Self-reported work-related illness and workplace injuries in 2007/2008: Results from the Labour Force Survey: National Statistics. 2009.

3. Global Burden of Disease Study 2013 Collaborators. Global, regional, and national incidence, prevalence, and years lived with disability for 301 acute and chronic diseases and injuries in 188 countries, 1990-2013: a systematic analysis for the Global Burden of Disease Study 2013. Lancet 2015;386:743-800.

4. Sanders T, Foster NE, Bishop A, et al. Biopsychosocial care and the physiotherapy encounter: physiotherapists' accounts of back pain consultations. BMC Musculoskelet Disord 2013;14:65.

5. Pincus T, Kent P, Bronfort G, et al. Twenty-five years with the biopsychosocial model of low back pain-is it time to celebrate? A report from the twelfth international forum for primary care research on low back pain. Spine 2013;38:2118-23.

6. Borenstein D. Mechanical low back pain-a rheumatologist's view. Nat Rev Rheumatol 2013:9:643-53.

7. Aspden RM. A new mathematical model of the spine and its relationship to spinal loading in the workplace. Appl Ergon 1988;19:319-23. 
8. McGill SM. The biomechanics of low back injury: implications on current practice in industry and the clinic. $J$ Biomech 1997;30:465-75.

9. Rohlmann A, Zander T, Graichen F, et al. Lifting up and laying down a weight causes high spinal loads. J Biomech 2013;46:511-4.

10. van Dieën JH, Hoozemans MJ, Toussaint HM. Stoop or squat: a review of biomechanical studies on lifting technique. Clin Biomech 1999;14:685-96.

11. HSE. Manual handling: manual handling operations regulations 1992. 4th edn, 2016

12. NIOSH. Ergonomic guidelines for manual materials handling. California: DHHS (NIOSH), 2007.

13. Farfan HF. The biomechanical advantage of lordosis and hip extension for upright activity. Man as compared with other anthropoids. Spine 1978;3:336-42.

14. Aspden RM. The spine as an arch. A new mathematical model. Spine 1989;14:266-74.

15. Crisco JJ, Panjabi MM, Yamamoto I, et al. Euler stability of the human ligamentous lumbar spine. Part II: Experiment. Clin Biomech 1992;7:27-32.

16. Patwardhan AG, Havey RM, Meade KP, et al. A follower load increases the load-carrying capacity of the lumbar spine in compression. Spine 1999;24:1003-9.

17. Han KS, Rohlmann A, Yang SJ, et al. Spinal muscles can create compressive follower loads in the lumbar spine in a neutral standing posture. Med Eng Phys 2011;33:472-8.

18. Dreischarf M, Bergmann G, Wilke HJ, et al. Different arm positions and the shape of the thoracic spine can explain contradictory results in the literature about spinal loads for sitting and standing. Spine 2010;35:2015-21.

19. Putzer M, Ehrlich I, Rasmussen J, et al. Sensitivity of lumbar spine loading to anatomical parameters. J Biomech 2016;49:953-8.

20. Boulay C, Tardieu C, Hecquet J, et al. Sagittal alignment of spine and pelvis regulated by pelvic incidence: standard values and prediction of lordosis. Eur Spine J 2006;15:415-22.

21. Scannell JP, McGill SM. Lumbar posture--should it, and can it, be modified? A study of passive tissue stiffness and lumbar position during activities of daily living. Phys Ther 2003;83:907-17.

22. Dryden IL, Oxborrow N, Dickson R. Familial relationships of normal spine shape. Stat Med 2008;27:1993-2003.

23. Stone MA, Osei-Bordom DC, Inman RD, et al. Heritability of spinal curvature and its relationship to disc degeneration and bone minera density in female adult twins. Eur Spine J 2015;24:2387-94

24. Keller TS, Colloca CJ, Harrison DE, et al. Influence of spine morphology on intervertebral disc loads and stresses in asymptomatic adults: implications for the ideal spine. Spine $J$ 2005;5:297-309.

25. Roussouly P, Gollogly S, Berthonnaud E, et al. Classification of the normal variation in the sagittal alignment of the human lumbar spine and pelvis in the standing position. Spine 2005;30:346-53.

26. Stagnara P, De Mauroy JC, Dran G, et al. Reciprocal angulation of vertebral bodies in a sagittal plane: approach to references for the evaluation of kyphosis and lordosis. Spine 1982;7:335-42.

27. Been $\mathrm{E}$, Barash A, Pessah $\mathrm{H}$, et al. A new look at the geometry of the lumbar spine. Spine 2010;35:E1014-E1017.

28. Pavlova AV, Meakin JR, Cooper K, et al. The lumbar spine has an intrinsic shape specific to each individual that remains a characteristic throughout flexion and extension. Eur Spine $J$ 2014;23(Suppl 1):26-32.

29. Meakin JR, Gregory JS, Aspden RM, et al. The intrinsic shape of the human lumbar spine in the supine, standing and sitting postures: characterization using an active shape model. J Anat 2009;215:206-11.

30. Endo K, Suzuki H, Nishimura H, et al. Sagittal lumbar and pelvic alignment in the standing and sitting positions. J Orthop Sci 2012;17:682-6.

31. Meakin JR, Gregory JS, Smith FW, et al. Characterizing the shape of the lumbar spine using an active shape model: reliability and precision of the method. Spine 2008;33:807-13.

32. Ali AH, Cowan AB, Gregory JS, et al. The accuracy of active shape modelling and end-plate measurements for characterising the shape of the lumbar spine in the sagittal plane. Comput Methods Biomech Biomed Engin 2012;15:167-72.

33. Besier TF, Sturnieks DL, Alderson JA, et al. Repeatability of gait data using a functional hip joint centre and a mean helical knee axis. $J$ Biomech 2003;36:1159-68.

34. Crewe H, Campbell A, Elliott BC, et al. The Relationship Between Shoulder Counter-Rotation and Lumbar Mechanics During Fast Bowling. Portuguese Journal of Sports Sciences 2011;11(Suppl 2):73-6.
35. Crewe $\mathrm{H}$, Campbell A, Elliott B, et al. Kinetic sensitivity of a new lumbo-pelvic model to variation in segment parameter input. $J$ Appl Biomech 2013;29:354-9.

36. Cootes TF, Hill A, Taylor CJ, et al. Use of active shape models for locating structures in medical images. Image Vis Comput 1994;12:355-65.

37. Cootes TF, Taylor CJ, Cooper DH, et al. Active Shape Models-Their Training and Application. Computer Vision and Image Understanding 1995;61:38-59.

38. Winter DA. Biomechanics and motor control of human movement. Hoboken: Wiley, 2005.

39. Wu G, Siegler S, Allard P, et al. ISB recommendation on definitions of joint coordinate system of various joints for the reporting of human joint motion--part I: ankle, hip, and spine. International Society of Biomechanics. J Biomech 2002;35:543-8.

40. du Rose A, Breen A. Relationships between lumbar inter-vertebral motion and lordosis in healthy adult males: a cross sectional cohort study. BMC Musculoskelet Disord 2016;17:1-9.

41. Breen A, Allen R, Morris A. An image processing method for spine kinematics-preliminary studies. Clin Biomech 1988;3:5-10.

42. Breen A, Allen R, Morris A. A digital videofluoroscopic technique for spine kinematics. J Med Eng Technol 1989;13:109-13.

43. Cholewicki J, McGill SM. Lumbar posterior ligament involvement during extremely heavy lifts estimated from fluoroscopic measurements. J Biomech 1992;25:17-28.

44. Aiyangar A, Zheng L, Anderst W, et al. Apportionment of lumbar L2-S1 rotation across individual motion segments during a dynamic lifting task. J Biomech 2015;48:3709-15.

45. Harvey S, Hukins D, Smith F, et al. Measurement of lumbar spine intervertebral motion in the sagittal plane using videofluoroscopy. $J$ Back Musculoskelet Rehabil 2016;29:445-57.

46. Srbinoska H, Dreischarf M, Consmüller T, et al. Correlation between back shape and spinal loads. J Biomech 2013;46:1972-5.

47. Kingma I, Faber GS, Bakker AJ, et al. Can low back loading during lifting be reduced by placing one leg beside the object to be lifted? Phys Ther 2006;86:1091-105.

48. Dolan P, Kingma I, van Dieen J, et al. Dynamic forces acting on the lumbar spine during manual handling. Can they be estimated using electromyographic techniques alone? Spine 1999;24:698-703.

49. Brinckmann P, Biggemann M, Hilweg D. Prediction of the compressive strength of human lumbar vertebrae. Clin Biomech 1989;4(Suppl 2):iii-27.

50. Hutton WC, Cyron BM, Stott JR. The compressive strength of lumbar vertebrae. J Anat 1979;129(Pt 4):753-8.

51. Hutton WC, Adams MA. Can the lumbar spine be crushed in heavy lifting? Spine 1982;7:586-90.

52. NIOSH. Work Practices Guide for Manual Lifting. Cincinnati, Ohio: US DHHS (NIOSH), 1981:1-183.

53. Waters TR, Putz-Anderson V, Garg A, et al. Revised NIOSH equation for the design and evaluation of manual lifting tasks. Ergonomics 1993;36:749-76.

54. Dolan P, Earley M, Adams MA. Bending and compressive stresses acting on the lumbar spine during lifting activities. $J$ Biomech 1994;27:1237-48.

55. Schmidt H, Kettler A, Heuer F, et al. Intradiscal pressure, shear strain, and fiber strain in the intervertebral disc under combined loading. Spine 2007;32:748-55.

56. Shirazi-Adl A, Ahmed AM, Shrivastava SC. A finite element study of a lumbar motion segment subjected to pure sagittal plane moments. $J$ Biomech 1986;19:331-50.

57. Miller JA, Schultz AB, Warwick DN, et al. Mechanical properties of lumbar spine motion segments under large loads. J Biomech 1986;19:79-84.

58. Klein JA, Hukins DW. Relocation of the bending axis during flexionextension of lumbar intervertebral discs and its implications for prolapse. Spine 1983;8:659-64.

59. Hickey DS, Hukins DW. Relation between the structure of the annulus fibrosus and the function and failure of the intervertebral disc. Spine 1980;5:106-16.

60. Kingma I, Faber GS, van Dieën JH. Supporting the upper body with the hand on the thigh reduces back loading during lifting. J Biomech 2016;49:881-9.

61. Jackson RP, McManus AC. Radiographic analysis of sagittal plane alignment and balance in standing volunteers and patients with low back pain matched for age, sex, and size. A prospective controlled clinical study. Spine 1994;19:1611-8.

62. Sheppard PS, Stevenson JM, Graham RB. Sex-based differences in lifting technique under increasing load conditions: A principal component analysis. Appl Ergon 2016;54:186-95. 